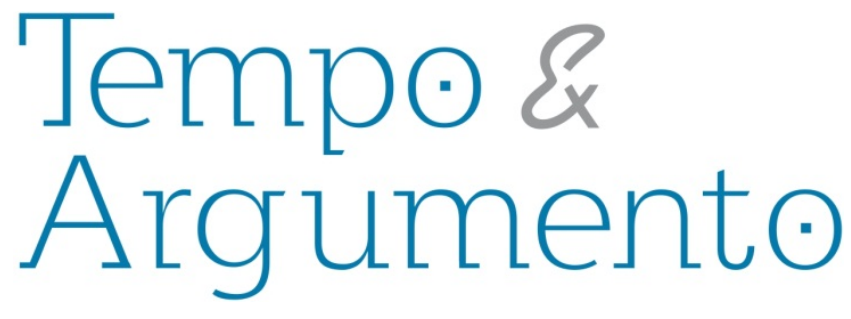

\title{
Humor e liberdades: um breve ensaio sobre ser Charlie
}

\begin{abstract}
Resumo
A violência perpetrada por alguns grupos fundamentalistas islâmicos nos últimos anos, em especial o assassinato dos chargistas franceses do Charlie Hebdo, no início de 2015, trazem à tona questionamentos nas sociedades ocidentais acerca da natureza de seu sistema econômico, de sua inserção global, da democracia e, particularmente, das liberdades. Este artigo toma algumas das charges de Maomé publicadas no jornal dinamarquês Jyllands-Posten, em 2005, e no jornal francês Charlie Hebdo, em 2012, e explora seu humor, sua violência e as reações que suscitaram. As breves reflexões resultantes da análise desses casos nos levam a uma discussão acerca da tradição "ocidental” da sátira, sobre a liberdade religiosa e a liberdade de expressão, além da própria ideia de democracia. São observadas teorias de autores clássicos, como Montesquieu e Stuart Mill, além de autores contemporâneos que pensaram as liberdades democráticas, como John Rawls e Pierre Rosanvallon, situando esse pertinente debate da contemporaneidade na longa duração. Este breve ensaio promove o debate acerca dos limites do humor, em especial em sua relação com religiões e com a política na contemporaneidade.
\end{abstract}

Palavras-chave: Humor; Liberdade; Democracia; Caricaturas e Desenhos Humorísticos, Maomé.

\author{
Vinícius Aurélio Liebel \\ Doutor em Ciência Política pela Freie \\ Universität Berlin - FUB. Professor da \\ Pontifícia Universidade Católica do Rio \\ Grande do Sul -PUCRS. \\ Bolsista Capes/PNPD. \\ Brasil \\ v.liebel@uol.com.br
}

\section{Para citar este artigo:}

LIEBEL, Vinícius Aurélio. Humor e liberdades: um breve ensaio sobre ser Charlie. Revista Tempo e Argumento, Florianópolis, v. 8, n. 18, p. 268 - 290. maio/ago. 2016. 


\title{
Humor and freedoms: a short essay on being Charlie
}

\begin{abstract}
The violence perpetrated by some Islamic fundamentalist groups in recent years, particularly the murder of the French cartoonists who worked for Charlie Hebdo, in early 2015, bring up doubts in the Western societies regarding the nature of their economic system, their global interconnection, the democracy, and specifically the freedoms. This article analyzes some cartoons of Muhammad published by the Danish newspaper Jyllands-Posten, in 2005, and by the French newspaper Charlie Hebdo, in 2012, and it explores their humor, their violence, and the reactions raised by them. The brief reflections derived from the analysis of these cases lead us to a discussion about the 'Western' tradition of satire, addressing religious freedom and freedom of expression, in addition to the very idea of democracy. Theories proposed by classic authors, such as Montesquieu and Stuart Mill, as well as those by contemporary authors who thought of the democratic freedoms, such as John Rawls and Pierre Rosanvallon are addressed, situating this relevant debate of contemporaneity in the long-term. This short essay promotes the debate about the limits of humor, especially in its relation to religions and politics nowadays.
\end{abstract}

Keywords: Humor; Freedom; Democracy; Cartoon; Muhammad. 
O que é Liberdade de expressão?

Sem a liberdade de ofensa, ela cessa de existir.

(Salman Rushdie)

\section{Introdução}

A tênue linha entre ofensa e perseguição, entre opinião e discurso de ódio, perpassa a citação de Rushdie. Sendo ele próprio o centro de uma das maiores controvérsias envolvendo religião, arte e opinião das últimas décadas, suas palavras ganham em peso ao abordarmos a questão da liberdade no trato público da religião. Elas mostram que nem toda característica identitária de grupos ou indivíduos está livre do escrutínio público e que as diferentes formas de representá-las ou criticá-las precisam ser constantemente debatidas, a fim de que não se perca nem a liberdade de opinião, por um lado, nem extrapole para o discurso de ódio, por outro. É esse o debate que trazemos neste breve ensaio, focando o caso específico das charges. O texto que se segue debate a natureza das imagens de Maomé publicadas no jornal dinamarquês Jylland-Posten e no jornal francês Charlie Hebdo, casos que geraram polêmicas semelhantes, para, em seguida, reconstruir a argumentação a favor das liberdades democráticas que ampara a publicação dessas charges. Em certa medida, debate-se os limites do humor, mesmo daquele que se reconhece como radical, e sua inserção no campo democrático, tomado, aqui, propositalmente como espaço abstrato e generalizado.

É nesse sentido que as liberdades serão tomadas como valores absolutos e idealtípicos, para que o debate não se prenda a minúcias específicas de cada país, de cada democracia. Com frequência, ao refletirmos sobre o problema da(s) liberdade(s) na contemporaneidade, tomamos por garantida a pressuposição da condição democrática e das liberdades que a acompanham, ainda que tal condição não tenha sequer completado trinta anos ininterruptos em nosso país e sofra, presentemente, abalos e dúvidas. Ainda, quando tais reflexões avançam para além da conjuntura brasileira, frequentemente temos dificuldades em dimensionar as liberdades e nos posicionarmos em suas caracterizações e sua defesa. 
No decorrer da última década, confrontamo-nos com dois casos bastante típicos dessa situação. As publicações das charges de Maomé, primeiro na Dinamarca, em 2005, depois na França, em 2012, irromperam uma onda de protestos e agressões por parte de fanáticos muçulmanos do mundo inteiro. A violência dessas reações levantou questionamentos em boa parte do Ocidente, levando a um dimensionamento das liberdades que são tidas como características inerentes às sociedades ocidentais. Neste artigo, buscamos verificar o lugar das liberdades de culto e de expressão à sombra desses casos, bem como dimensionar as fronteiras dessas liberdades e analisar se elas foram ultrapassadas com a publicação dessas imagens.

Charges e cartuns são naturalmente polêmicos por conterem em si a crítica travestida de sátira, que, como Bergson (2001) já afirmou, desempenha uma função social de reordenamento da sociedade que ocorre através do efeito humilhante da comicidade crítica. Seguindo a lógica bergsoniana, esses desenhos, assim como o humor de maneira geral, quando apontam seus alvos, estariam mostrando os erros e as idiossincrasias presentes na sociedade e buscando, de alguma forma, corrigi-los. Estariam, portanto, agindo afirmativamente na sociedade, promovendo o debate e a ridicularização dos problemas sociais e de atores individuais. Para seus principais críticos, o elemento humilhante, indissociável das charges em muitos casos, configuraria essas representações como nocivas à sociedade, em oposição ao defendido por Bergson (2001).

\section{As charges e a sociedade}

As charges continuam desempenhando um papel fundamental nos debates contemporâneos, a despeito dos críticos e detratores de seu humor. Essa violência, que humilha e toma partido, está presente em praticamente todas as charges e, mesmo assim, talvez nunca tantos chargistas tenham trabalhado e visto seus produtos divulgados para um público virtualmente infinito - como ocorre na internet. Isso permite levantar algumas perguntas, como: as charges são realmente perigosas e ofensivas? Existem fronteiras para a pilhéria? Onde termina a sátira e começa o ataque? Essas 
perguntas se relacionam intimamente com o contexto em que são produzidas, com o papel das charges em diferentes regimes e sociedades, pois a utilização e percepção de suas mensagens tendem a se modificar de acordo com a atmosfera gerada pelo ambiente político, as estruturas vigentes em dada sociedade e a cultura política que as perpassa.

Tendo como alvo de suas críticas e sátiras essencialmente elementos presentes na arena pública da sociedade, as charges e os cartuns pisam sempre em um campo minado, onde a mensagem flerta constantemente com a calúnia e a difamação. Como seus produtores conseguem seguir com seus ofícios, sem ser processados e condenados por suas opiniões? Elmar Erhardt (1988) esclarece que charges e cartuns devem ser entendidos como uma "forma especial de sátira" e, por isso, chargistas e jornais raramente são condenados em processos movidos em razão de suas críticas. Além disso, as liberdades de imprensa, de opinião e de expressão desempenham um papel central na teia sistemática que resulta na proteção dos chargistas e cartunistas.

A natureza satírica desses desenhos causa, entretanto, variadas controvérsias que podem acarretar não apenas consequências penais. Charges e cartuns estão no centro de questões políticas e sociais. São partes ativas da imprensa e participam, nessa condição, da constante vigilância política e social (surveillance, no sentido adotado por Rosanvallon, (2006)). Eles tomam de empréstimo elementos do imaginário de uma sociedade e frequentemente os subvertem, exageram ou carregam com algum significado diverso daquele normalmente atribuído a eles, e o fazem para reforçar seu discurso e tornar mais claro o ponto de vista defendido. No papel de vigilantes do sistema, esse conjunto de ações é adotado na denúncia de pontos controversos, quando não na defesa da sociedade. Nesse sentido, as liberdades acima elencadas são uma necessidade. 


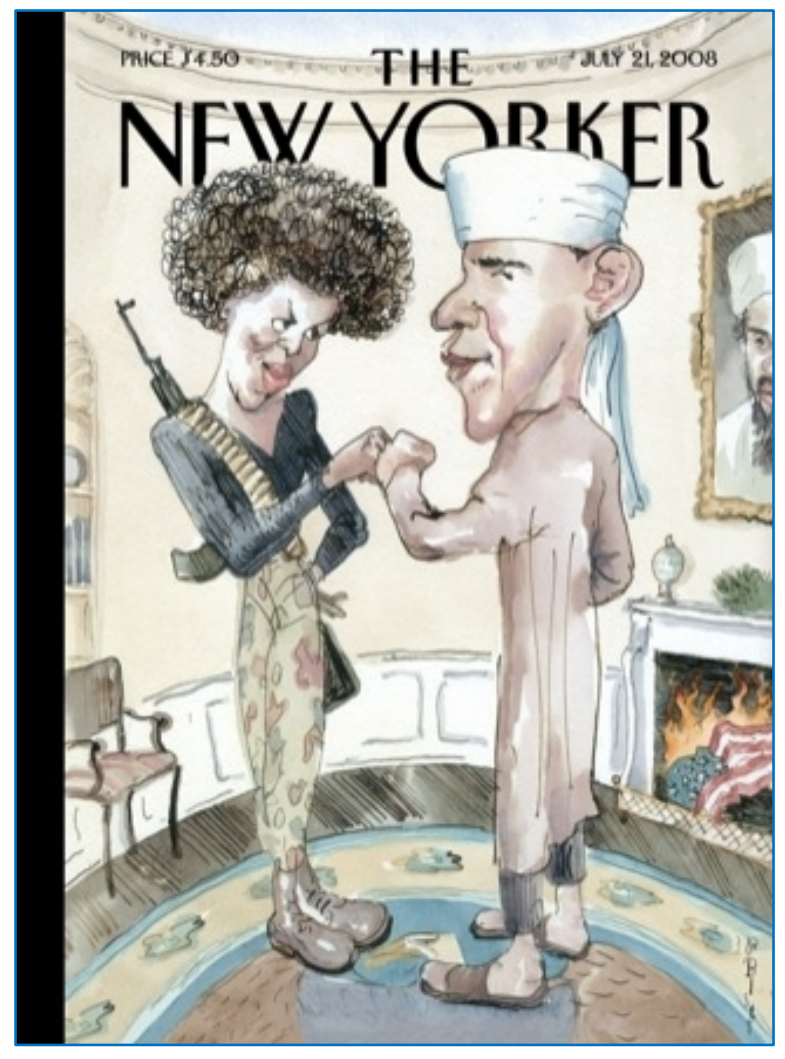

Figura 1 - BLITT, Barry. The Politics of Fear. Fonte: The New Yorker. 21 Jul. 2008.

Quando a imagem acima foi publicada na capa da revista New Yorker, uma discussão acalorada acerca do papel dos chargistas teve lugar nos Estados Unidos. A representação do presidente Obama como um muçulmano fundamentalista antiamericano e da primeira-dama como uma guerrilheira sofreu inúmeros ataques, e a crítica contida na charge foi rejeitada como impregnada de preconceitos. As feições e “traços permanentes” (TÖPFFER, 2003) de suas representações também não poderiam ser exagerados. De acordo com os críticos, eventuais exageros nesses elementos do desenho revelariam uma representação racista, diminuindo o presidente e todo o grupo afro-americano ao carregar sua representação com traços tomados por tipicamente símios. Tais considerações tiveram como resultado o alívio das críticas a Obama e ao seu governo (WASHINGTON, 2009). Os chargistas acabaram por se conter nas críticas e nas representações, para que não pesasse sobre eles a sombra do racismo. Essa situação inaugurou nos Estados Unidos um debate aberto sobre racismo e sobre o papel das charges na imprensa e os chargistas puderam voltar a criticar o governo sem se 
preocupar com acusações de preconceito racial. Da mesma forma, esse debate resultou em uma mudança qualitativa na percepção do público sobre seu trabalho. As fronteiras entre a crítica e o racismo se tornaram mais claras para o público: o conceito de racismo foi debatido e ficou demonstrado que a crítica a um presidente afrodescendente não é necessariamente uma crítica por ele ser afrodescendente.

Outro debate acerca do humor na arena pública teve lugar no Brasil, durante as eleições presidenciais de 2010. O foco da contenda foi o artigo 45, inciso II, do Decreto-Lei n. 9.504/1997 (BRASIL, 1997), que proibia a mídia de "usar trucagem, montagem ou outro recurso de áudio ou vídeo que, de qualquer forma, degradem ou ridicularizem candidato, partido ou coligação, ou produzir ou veicular programa com esse efeito". Em outras palavras, proibia humoristas da mídia falada e escrita de mencionar os políticos durante o período eleitoral, privando seus ouvintes, leitores e espectadores da sátira crítica.

A base para essa proibição estava assentada sobre o fato da sátira política ter, em sua essência, uma natureza político-partidária, uma vez que seus produtos terão sempre um posicionamento em relação ao elemento satirizado (em concordância, mais uma vez, com a teoria do humor de Bergson (2001)). Isso poderia caracterizar propaganda, o que iria diretamente contra o inciso seguinte da mesma lei das eleições. Consideraçõos psicanalíticas também entraram no debate, especialmente a teoria freudiana do arrebanhamento de partidários pelo prazer proporcionado pelo riso (FREUD, 2006). Entretanto, apesar das pressuposições estarem corretas (uma piada política é essencialmente um posicionamento político), a proibição atinge princípios superiores da liberdade de opinião e expressão. Esse foi também o entendimento do Supremo Tribunal Federal (STF), que acabou por suspender o dispositivo da lei (SUPREMO TRIBUNAL FEDERAL 2010).

\section{Religião e humor: apresentação dos casos das charges de Maomé}

Os casos aqui relatados ilustram com precisão a natureza controversa das charges e dos cartuns, bem como demonstram o fato de que o humor é elemento premente na sociedade contemporânea. Mostram a facilidade com que são questionadas e como 
atingem, ainda que indiretamente, o âmago das representações político-sociais que retratam. Mas o debate público em torno das charges e cartuns ganhou em complexidade nos últimos anos, quando algumas representações religiosas se tornaram objeto de discussão.

Em setembro de 2005, doze cartuns que continham representações do profeta muçulmano Maomé foram publicados no jornal dinamarquês Jylland-Posten. Tais desenhos derivaram de um concurso promovido pelo impresso, que buscava indagar os artistas sobre a autocensura que se impunha na Dinamarca e na Europa quando o assunto retratado era o Islã. Poucos foram os que responderam ao anúncio e um grupo de imagens foi publicado, então, em 30 de setembro de 2005, sob o título "Faces de Maomé". Os desenhos desencadearam protestos de islâmicos do mundo todo (PROTESTOS, 2006), e o jornal e os desenhistas dinamarqueses receberam apoio de vários outros meios de comunicação, especialmente na Europa (JORNAIS, 2008). Alguns chegaram a republicar as charges em suas páginas para reafirmar seu compromisso com a liberdade de expressão. Com isso, os cartuns de Maomé acabaram por iniciar um debate em todo o globo acerca do papel social e político das charges e cartuns e sua relação com a liberdade de expressão.

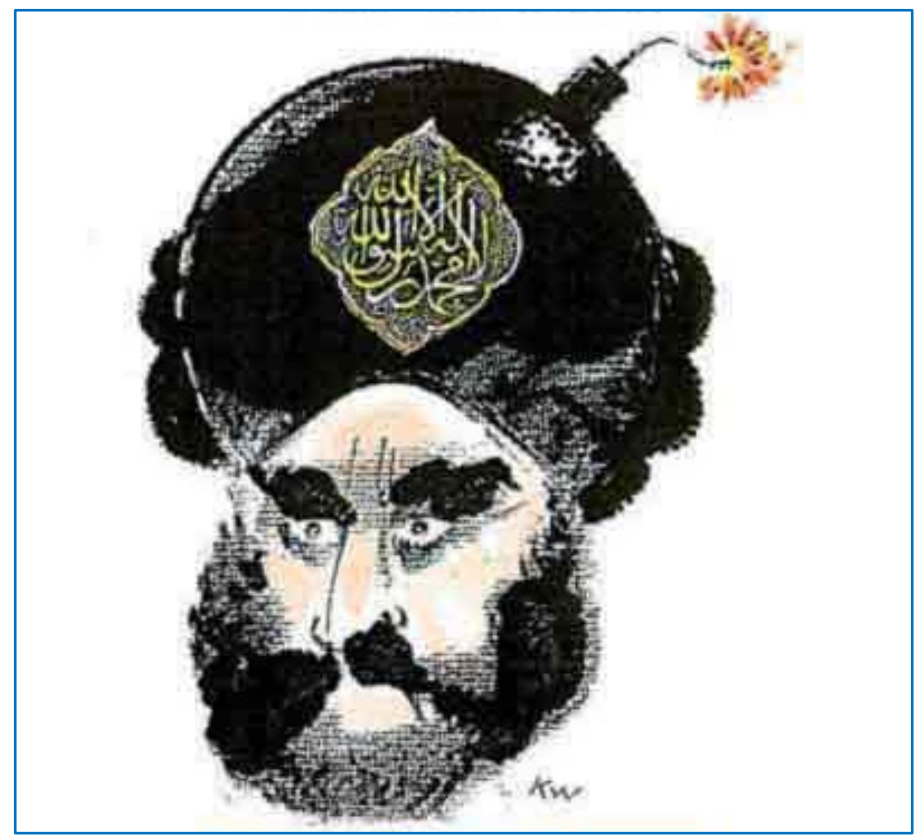

Figura 2 - WESTERGAARD, Kurt. Muhammed. Fonte: Jylliands Posten. 30. Sep. 2005. p.3. 
Como descrito por Dawkins (2007, p. 51):

\begin{abstract}
Jornais na Noruega, na Alemanha, na França e até nos Estados Unidos (mas, notavelmente, não na Grã-Bretanha) republicaram as caricaturas num gesto de solidariedade ao Jyllands-Posten, o que pôs mais lenha na fogueira. Embaixadas e consulados foram depredados, produtos dinamarqueses foram boicotados, cidadãos dinamarqueses - e até ocidentais em geral - foram fisicamente ameaçados; igrejas católicas no Paquistão, sem nenhum tipo de ligação com dinamarqueses ou europeus, foram incendiadas. Nove pessoas morreram quando manifestantes líbios atacaram e incendiaram o consulado italiano em Benghazi.
\end{abstract}

A busca pelas razões dos protestos dos muçulmanos, por sua vez, resultou em dois motivos principais:

1 - Os cartuns retratam pictoricamente o profeta Maomé, o que é proibido pelas leis islâmicas. Nesse ponto, trata-se de uma especificidade do Islamismo e o jornal e os desenhistas estavam bem ancorados na retórica legislativa. A proibição da representação de Maomé é uma regra que concerne exclusivamente aos membros dessa religião. $\mathrm{A}$ liberdade de credo opera, aqui, em uma via de mão dupla: em Estados onde existe tal liberdade (caso de Dinamarca e França), uma norma específica de uma determinada religião não pode ser imposta aos não seguidores de tal credo, assim como proibições específicas também não o podem. Nos Estados democráticos, a laicidade é característica dominante e, ainda que religião não esteja sempre desvinculada do Estado (o caso de Israel é o mais evidente aqui), a liberdade religiosa é um dos princípios fundamentais que todos compartilham. Fica assim evidente a impossibilidade da imposição de um dogma específico de uma religião sobre toda a população nesses Estados.

2 - O segundo argumento contra os cartuns defendia que os desenhos de Maomé iam contra a dignidade dos crentes muçulmanos, tomando a violência - e especificamente o terrorismo - como elemento generalizado e inerente à religião, caracterizando assim um ataque aberto contra eles. Essa premissa abre caminho para outro questionamento. 
Trata-se da interpretação dos desenhos, ou seja, refere-se à polissemia das charges e dos cartuns. O cartum da figura 2 é analisável de formas variadas. Pode ser interpretado, por exemplo, como a representação de uma (auto)implosão do Islã. Através dele, pode-se chegar à conclusão de que o terrorismo e as linhas fundamentalistas do Islamismo acabam por enfraquecer a religião. A imagem mostraria, então, a religião como maior vítima da violência terrorista. O (fraco) humor denunciaria uma religião a caminho da extinção, próxima do ponto de “explosão”, e Maomé seria aqui tomado como alegoria para todo o Islã. Essa interpretação não seria, de forma alguma, uma forma de difamação. As manifestações contra o desenho mostraram, entretanto, que essa não foi a análise feita pela maioria (DIÈNE, 2006). E, apesar de alguns analistas terem apontado diferentes motivos para esses protestos ${ }^{1}$, as discussões públicas concentraram-se principalmente na liberdade de expressão e de opinião.

Desenvolvimento semelhante dos acontecimentos teve o caso dos cartuns publicados no jornal Charlie Hebdo, em 2012. Aqui, os desenhos foram uma reação a um evento prévio, qual seja, o vazamento na internet de trechos do filme Innocence of Muslims, de Mark Youssef. No filme, de qualidade muito discutível, são retratados episódios da vida do profeta Maomé, sempre de forma bastante satírica. A figura do profeta foi assim não apenas retratada na película, mas caricaturada, abrindo espaço para novos protestos ${ }^{2}$ do mundo islâmico, a exemplo do ocorrido em 2005.

Como reflexo dos eventos acima citados, o jornal Charlie Hebdo publica em Paris, na mesma semana (19 de setembro de 2012), sua edição satirizando as reações ao filme. A exemplo do próprio filme de Mark Youssef, os cartuns demonstram escárnio a respeito do profeta, retratando um Maomé em poses de gosto bastante duvidoso em frente às câmeras.

\footnotetext{
${ }^{1}$ As manifestações contra os cartuns ocorridas no mundo islâmico foram apontadas por alguns analistas como a última arma de alguns regimes "para evitar sua própria destruição" (KORNELIUS, 2006, apud $P A ̈ G E, 2007)$. A desestabilização de regimes (como no Paquistão, Nigéria etc.) também foi apontada como motivo para os protestos (KLAUSEN, 2009). Essas explicações para as manifestações não focam a liberdade de expressão nem a liberdade religiosa, mas, sim, o conflito entre Ocidente e Oriente, isto é, a cultura islâmica fundamentalista. Segundo essa linha de raciocínio, "os desenhos não seriam o motivo dos protestos, mas sim seu gatilho" (PÄGE, 2007, p. 168).

2 Em seu ápice, os protestos se espalharam para outros países do Oriente Médio, o norte e o centro da África, atingindo o Sudão, a Síria, Israel, Jordânia, o lêmen e o Egito, chegando ao Afeganistão e à Indonésia.
} 


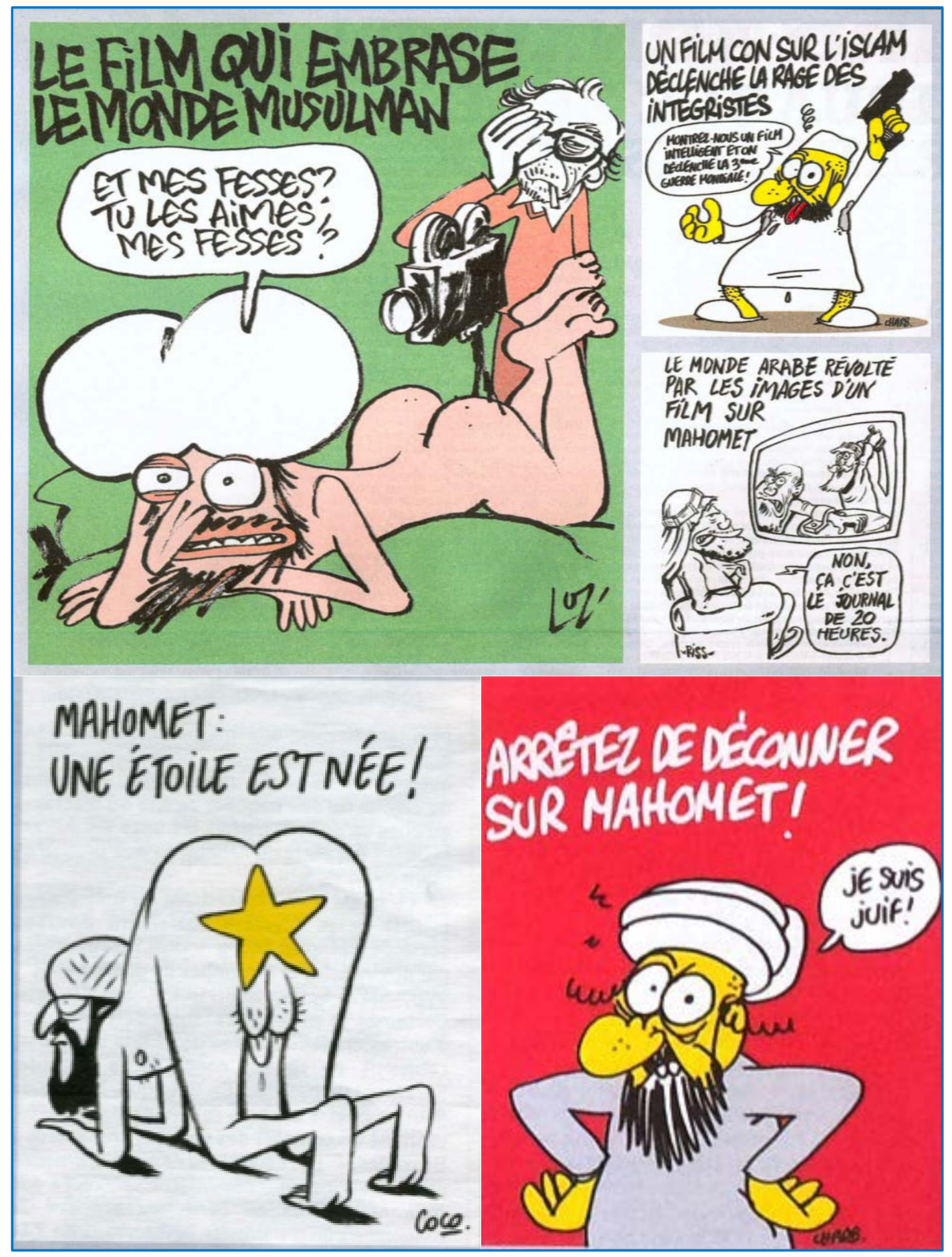

Figura 3 - COCO et. al.

Fonte: Charlie Hebdo. Paris, 19 de setembro de 2012. p. 14.

Como no caso do ano de 2005, os cartuns franceses não conclamam à perseguição dos muçulmanos nem contêm em seu núcleo uma declaração de ódio contra a religião e seus seguidores. Da mesma forma, o filme, apesar de mal acabado e grosseiro, em momento algum incita os "ocidentais" a uma cruzada contra os islâmicos. Entretanto, os 
cartuns e o filme de 2012 não receberam o mesmo apoio que os desenhos de 2005. De fato, foram abertamente criticados e o filme foi censurado em alguns países 3 . Entretanto, existe alguma fundamentação para proibir esses artefatos? As críticas neles contidas dão margem à censura? A liberdade de expressão entra aqui em confronto com a liberdade de culto?

\section{Liberdades de culto e de expressão: elementos de um debate presente}

Essas indagações são aqui respondidas negativamente, e nas próximas páginas embasamos essas respostas através de fundamentos teóricos que estão intrinsecamente ligados ao estado atual de grande parte dos Estados democráticos do Ocidente.

A primeira questão aberta se refere à caracterização de liberdade, enquanto conceito e enquanto práxis. Aqui também diferentes posições foram tomadas. Segundo a tradição de Montesquieu (2008, p. 243), a liberdade é "o direito de fazer tudo aquilo que as leis permitem, e, se um cidadão pudesse fazer aquilo do que as leis o defendem, ele ainda assim não seria livre, pois todos os outros também teriam o mesmo poder”. Mas onde ficam as fronteiras dessa liberdade - se é que elas existem?

Uma linha libertária extremista defende que não deve haver qualquer limitação nesse campo. Que as pessoas devem poder se expressar livremente, independente da opinião, do pensamento e do sentimento de terceiros. Defende-se, ainda, que ninguém deveria ter uma opinião ou crença permanentemente formada, uma vez que preconcepções limitam o desenvolvimento das discussões. Para essa linha de pensamento, "uma estratégia para evitar confrontos socialmente perigosos sobre crenças fixas é tentar se livrar das crenças fixas" (RAUCH, 1993, p. 102).

Essa linha argumentativa, antes de defender a dignidade humana e sua liberdade indiscriminada de expressão com base na liberdade e na responsabilidade individual, parece garantir que qualquer forma de crítica e ofensa seja permitida, visto que a crítica

\footnotetext{
${ }^{3}$ Dentre esses países encontra-se o Brasil, que, por meio de decisão do juiz Gilson Delgado Miranda, proibiu o trailer e qualquer imagem dele obtida para ser veiculada no YouTube. Assim, sob pena de multa diária de $\mathrm{R} \$ 10.000,00$, o site foi obrigado a retirar os vídeos relacionados ao filme do ar, decisão que viria a ser suspensa posteriormente (GAZETA DO POVO, 2012).
} 
seria feita com a pressuposição da racionalidade, ainda que esteja pautada em crenças e gostos. Ela se aproxima das justificativas que propiciaram o surgimento de publicações extremistas em diferentes momentos da história. Trata-se, aqui, de publicações que atacam a natureza de determinadas pessoas e grupos sociais. Assim, a crítica, isto é, o ataque, seja a raças, ideologias ou a grupos religiosos, seria justificada e permitida. A esse respeito, o filósofo Karsten Weber (2007, p. 42) escreve:

Normalmente o que se argumenta em relação às fronteiras da liberdade de opinião e de expressão é que se poderia evitar que as mídias de massa fossem usadas para propagar, de forma legal, ideias racistas e outras formas de "hate speech" contra indivíduos ou grupos, quer dizer, contra minorias religiosas ou étnicas. Caso existissem diretrizes para determinar que conteúdo pudesse ser propagado, seria possível evitar tais declarações e possivelmente processar judicialmente os responsáveis. Mas a estipulação de limites para a liberdade de expressão tem no mínimo duas desvantagens. Em primeiro lugar, um direito fundamental e necessário para a existência do Estado de direito democrático seria reprimido. Ainda mais problemática é a necessidade da existência de uma instância que decidiria com base em critérios contingentes se expressões excedem ou não os limites estabelecidos por tal lei. Visto não ser possível formular em detalhes o que deve ser proibido e o que pode ser permitido, tais regras precisariam ser tomadas de forma muito ampla. Com isso, entretanto, se abrem as portas para a interpretação arbitrária e oportunista. Isso é percebido de forma clara através do exemplo dos debates sobre os cartoons de Maomé, pois podemos perguntar: como essas imagens precisariam parecer para que se tornassem aceitáveis? 0 que seria permitido que mostrassem, o que não seria? Mas também se faria necessária a questão: quem tem permissão de proibi-la?

As questões levantadas por Weber (2007) mostram a complexidade do problema. Isaiah Berlin (2004, p. 11) afirmou, também sobre os problemas que envolvem a liberdade, que "não podemos permanecer totalmente livres, e precisamos abrir mão de parcelas da nossa liberdade para preservar o restante. Mas uma autorrendição completa é uma derrota autoimposta". A dinâmica política e social necessita de diversidade para que as qualidades e ideias individuais possam ser preservadas. Através da diversidade, ideias são geradas e a sociedade se desenvolve - essa é uma das premissas do Estado democrático. A troca de experiências, ideias e pontos de vista pessoais promovem o conhecimento e o combate de mitos e preconceitos. O caso das charges de Maomé é emblemático mais uma vez. Os protestos e as discussões que se seguiram às publicações reavivaram 
questões que colocaram em xeque alguns mitos e visões preconcebidos sobre o Islã no Ocidente. Preconceitos contra muçulmanos ainda existem no Ocidente, é claro, da mesma forma que existiam antes das publicações. Entretanto, o debate certamente contribuiu para uma análise crítica e para um esclarecimento parcial a seu respeito. As charges e os cartuns participaram, portanto, de forma ativa na arena pública e evidenciaram o papel determinante que a imprensa e, como parte dela, os chargistas e cartunistas desempenham na sociedade democrática.

\section{A religião satirizada: considerações sobre a liberdade de expressão}

As charges de Maomé proporcionam um interessante caso de estudo, tanto no tocante ao choque de culturas que elas representam quanto ao grau de adaptabilidade que as sociedades ocidentais estão dispostas a assumir para evitar choques ainda maiores. Formam, também, um caso interessante para analisar o estado atual das liberdades no Ocidente.

Nesse sentido, o primeiro ponto a ser salientado é que os jornais em questão, tanto o Jylland-Posten como o Charlie Hebdo, não promovem uma perseguição sistemática contra árabes ou muçulmanos. Diferenciam-se, portanto, de publicações tipicamente persecutórias e que promoviam o discurso de ódio contra determinados grupos sociais, como o jornal Der Stürmer ${ }^{4}$ alemão e o jornal ruandês Kangura ${ }^{5}$. Nesses dois impressos, as representações pictóricas e humorísticas eram sistematicamente apresentadas com vistas a infamar os grupos perseguidos, os judeus no primeiro caso e os tútsis no segundo. Nos casos dos jornais dinamarquês e francês não há perseguição

\footnotetext{
${ }^{4}$ O Der Stürmer foi um jornal semanal sediado em Nurembergue que cumpria duas funções: a primeira era a de apoiar o Partido Nazista e divulgar sua ideologia, a segunda era a de estabelecer os parâmetros do antissemitismo intrínseco ao ideário nacional-socialista. Seu fundador, Julius Streicher, foi condenado à morte no Tribunal de Nurembergue pelo desenvolvimento e propagação do antissemitismo virulento que era característico do Stürmer. Mais sobre o jornal e a construção do inimigo judeu em suas páginas, ver: BYTWERK, 2001; SHOWALTER, 1982; LIEBEL, 2011a e LIEBEL 2011b.

${ }^{5}$ Kangura foi uma revista ruandesa, publicada entre os anos de 1990 e 1994, que participou ativamente na construção do ambiente de hostilidade necessária para a implementação da perseguição e do posterior genocídio contra os tútsis em Ruanda. Em sua linha editorial, a intolerância contra o grupo tútsi estava presente em todos os artigos e charges, em forte semelhança com o jornal alemão Der Stürmer no período anterior ao Holocausto (ver KABANDA, 2007).
} 
sistemática. Ainda é possível diferenciar o tom da sátira e das mensagens que as charges e os cartuns trazem nos casos em comparação: tanto o Der Stürmer quanto o Kangura pregavam a eliminação do elemento retratado de suas sociedades. O discurso de ódio neles retratado é apologético da violência e incita uma visão que rebaixa os grupos satirizados. Existe, de fato, uma conclamação à ação violenta direta contra judeus e tútsis. Tal não se confirma nas representações de Maomé.

É necessário, ainda, caracterizar as charges e os cartuns quanto ao elemento satirizado, caracterização esta que nos parece crucial na determinação do mérito dos ataques e das denúncias contra seu conteúdo. Jornais como o Der Stürmer e o Kangura atacam e satirizam propriedades imanentes das pessoas e grupos sociais retratados (ser tútsi não é uma questão de opinião ou escolha). $O$ alvo de seus desenhos era a diminuição de uma "raça" (dos judeus e dos tútsis), ou seja, a desumanização do grupo sociorracial através de sua difamação. Também quando acusam tais grupos de promover a falsidade ou a imoralidade por meio de suas ações, essas ações seriam frutos, em última instância, de uma natureza degenerada e intrínseca ao grupo em questão. No caso dos desenhos de Maomé, não existe uma generalização como as dos dois casos acima.

Ainda, e aqui um elemento crucial quando a liberdade de expressão é posta em questão, o tema religioso não tem a mesma natureza quando comparado às questões ditas raciais. Essas últimas são reconhecidas enquanto elementos imanentes, ou seja, fazem parte da identidade genética dos indivíduos, não de suas escolhas. Um ataque generalizado a essas características é um ataque à própria natureza da pessoa. Este é o objetivo de charges e de cartuns veiculados no Der Stürmer e no Kangura: diminuir e humilhar grupos de indivíduos em sua natureza, classificá-los como naturalmente inferiores e/ou nocivos. Tal não é o caso da crítica e da sátira contra religiões, pois essas se referem ao campo das opiniões.

A proposição acima pode ser defendida pela caracterização do conceito de religião, que difere do conceito de fé, ainda que os dois se entrelacem em sua observação praxiológica. Se a existência de um ou de vários deuses é uma questão de fé por não poder se enquadrar nem no campo do conhecimento (não há base empírica para tal) nem no da opinião (não pertence $(m)$ ao mundo dos sentidos), conformando-se, assim, a uma 
existência especulativa transcendental apoiada apenas na fé (KANT, 2010), tal não é o caso da religião em si. Essa se caracteriza pela experiência sensitiva, constituindo-se primariamente de uma práxis, de um conjunto teórico-moral fundado em uma mitologia que dá sustentação, ou, antes, guiando as ações e os pensamentos de seus seguidores em conformidade com uma crença teleológica específica. Em outras palavras, as religiões são sistemas de ideias. É, entretanto, patente que uma infinidade de estruturas religiosas nesses moldes está à disposição para ser analisada, ponderada e escolhida. Ainda que um indivíduo tenha crescido em um núcleo familiar religioso e siga suas tradições, em uma sociedade democrática, a continuidade dessa práxis é determinada por uma escolha de seguir tal visão em detrimento de outras. Aqui se caracteriza a opinião, ou seja, a ideia de que uma linha religiosa é melhor ou mais apta a realizar os anseios pessoais na ordem teleológica da fé. A crítica à religião ou a preceitos religiosos, portanto, é uma crítica a essa opinião, sendo assim resguardada e protegida pela liberdade de expressão.

A premissa de que, pela crítica e pela sátira expostas nas charges, a liberdade de expressão pode interferir na liberdade de culto é outra questão que se abre nos debates aqui estabelecidos. Isso porque, segundo o princípio da prioridade da liberdade de Rawls (2002), as liberdades podem acabar por se autocercear, uma vez que o exercício de uma acarrete o prejuízo de outra. Nesse cenário, aquela que prejudica deve ser julgada em sua condição de liberdade básica e, após sua classificação, deve ser buscado o equilíbrio para o desenvolvimento de ambas.

Como as liberdades básicas podem ser limitadas quando entram em conflito umas com as outras, nenhuma dentre elas é absoluta e não se pode exigir, uma vez instalado o sistema final, que todas as liberdades básicas sejam tratadas igualmente (qualquer que seja o sentido de tal exigência). (RAWLS, 2002, p. 150).

Trata-se, mais uma vez, da afirmação de Isaiah Berlin (2004), já citada. É necessário ceder em alguns casos, a fim de que seja possível gozar das liberdades da forma mais plena possível. 
As religiões, assim como qualquer opinião, ao serem expressas na arena pública de debates, tornam-se passíveis de serem comentadas e criticadas. A liberdade de expressão não fere, portanto, a liberdade de religião, uma vez que ela não coíbe a escolha. A violência intrínseca a toda charge ou cartum que satirize uma religião não é impeditiva do exercício da fé ou do culto escolhido nem do direito do indivíduo de escolhê-lo. Entretanto, proibir que um indivíduo aponte criticamente elementos de uma religião, satirize-os ou manifeste uma opinião sobre eles viola o direito de liberdade de expressão. A determinação da Justiça de São Paulo que obrigava o YouTube a impedir o acesso ao vídeo Innocence of Muslims no Brasil deve ser analisada sob esse ponto de vista. Já os manifestantes pacíficos que protestavam contra as charges e o filme em diversas partes do mundo estavam exercendo, legitimamente, não sua liberdade religiosa, mas sua liberdade de crítica e de expressão contra os próprios críticos. Desnecessário dizer que o atentado contra a redação do Charlie Hebdo, em 8 de janeiro de 2015, está em um nível completamente diferente de ação.

Alguns podem argumentar que não importa o grau de introjeção de uma religião em um indivíduo ou uma comunidade, tampouco sua natureza opinativa na arena pública. Uma crítica ou sátira contra um elemento sensível, como o é a religião, deveria ser punida, pois agride, humilha e ofende aqueles que creem. Entretanto, até que ponto as opiniões vinculadas à religião, escolhas de foro íntimo transpostas para o debate público, devem receber um tratamento diferenciado que não é estendido a outras formas de opinião? O fato do indivíduo poder assimilar tais críticas como ofensa ou agressão (e não como mera opinião divergente) deve ser levado em consideração? Nas palavras de John Stuart Mill (2011, p. 87):

[...] pois se o teste for o fato de aqueles cuja opinião é atacada ficarem ofendidos, penso que a experiência demonstra que haverá uma ofensa sempre que o ataque for eficaz e poderoso, e que qualquer oponente que puxe muito por eles (e a quem eles tenham dificuldade em responder) Ihes parece imoderado, bastando para tal que mostre um sentimento forte sobre o assunto.

É nesse sentido que as liberdades políticas se retroalimentam, e as críticas exercidas por um chargista, sejam elas de cunho social, religioso ou político, antes da 
ofensa servem à reflexão de sua própria sociedade. Os desenhistas do Charlie Hebdo, herdeiros dos iluministas radicais (ver ISRAEL, 2009), não se prendem ao respeito ou à reflexão empática na expressão de suas opiniões. Nesse sentido, alinham-se perfeitamente àquilo que Gertrude Himmelfarb (2011) descreveu como a ideologia da razão, ou seja, a herança iluminista, ligada pela autora principalmente à França, de defender e exercer plenamente a razão, perdendo de vista valores subjetivos.

\section{Conclusão}

Manifestações culturais e eventuais controvérsias e protestos delas decorrentes (como os casos aqui analisados) são eventos que ilustram o delicado momento sociocultural que a evolução da globalização nos apresenta. Trata-se de muito mais do que um choque de civilizações, na expressão consagrada por Huntington (1997); é um longo processo de conformação cultural que a exponencialmente elevada troca de experiências verificada nas últimas décadas nos legou.

Nesse contexto, parece fácil para nós, indivíduos inseridos em uma cultura ocidental democrática, ver as "evoluções" da influência de nossa forma de vida, de nossa visão de mundo, sobre o Oriente. Conseguimos julgar com clareza as primaveras pelo mundo como eventos detonados e determinados por nosso exemplo, e estamos muitas vezes prontos a justificar guerras em nome da expansão dos valores democráticos. Mais difícil parece ser a integração e aceitação das diferenças culturais em nosso próprio espaço. Algumas pesquisas do Instituto Gallup, por exemplo, mostram que a opinião negativa dos cidadãos norte-americanos em relação aos muçulmanos bate na casa dos 50\% (GALLUP INSTITUTE, 2012a), enquanto 21\% da população alemã e 16\% das populações francesa e inglesa sentem aversão à possibilidade de ter um vizinho muçulmano (GALLUP INSTITUTE, 2012b). Entretanto, esse ambiente de hostilidade não está reservado apenas aos islâmicos; as mesmas pesquisas mostram que, ainda que em menor grau, judeus, cristãos e ateus também contam com sua parcela de suspeição e preconceito.

O surgimento dessa atmosfera de conflitos eminentes produziu sociedades que tratam, com razão, suas questões sensíveis de forma mais zelosa. É nesse contexto que 
opiniões contraditórias, como as expostas nas charges de Maomé, disparam o alerta do medo. Na busca pelo equilíbrio, tem-se mostrado frequente, entretanto, a tentação da censura. A contraposição de opiniões em questões sensíveis - e o humor sobre elementos religiosos parece ser um ponto particularmente delicado em nosso tempo tem resultado em ações e posicionamentos cada vez mais desfavoráveis às liberdades individuais.

O silenciamento por meio de censura ou de intimidação daqueles que têm uma opinião que contradiz a maioria ou uma grande parcela da população (o tema da religião pode ser assumido como tal, visto que boa parte da população possui uma crença ou uma religião) pertence à tradição autoritária das ditaduras, não à herança do liberalismo democrático, como aqui demonstrado. Esse prima não apenas pela liberdade de expressão, mas também pelo debate aberto e igualitário, e guia-se pela ideia de que mesmo

[...] quando há pessoas que constituem uma exceção à aparente unanimidade do mundo sobre qualquer assunto, mesmo que o mundo esteja do lado certo, é sempre provável que os que discordam tenham a dizer algo que valha a pena ouvir, e que a verdade perderia algo com seu silêncio (STUART MILL, 2011, p. 81).

Os debates e as discussões que os cartuns e as charges provocam também servem, em um cenário ideal, à expansão da liberdade e da tolerância na sociedade. E os debates são o caminho para o controle dos extremismos - não apenas na política, no governo e na religião, mas dos próprios cartunistas. A censura contra questões puras de opinião provocam o entrave desses desenvolvimentos. De fato, pode-se argumentar nesse sentido, junto com Thomas Jefferson (1777), que em seu Estatuto da Virgínia para a Liberdade Religiosa condenou a censura contra opiniões religiosas e sobre a religião, alegando que "erros [deixam] de ser perigosos quando se é permitido contradizê-los livremente". A expressão da opinião religiosa está, portanto, intimamente relacionada à liberdade de expressão em uma sociedade democrática, não em uma padronização das consciências. Limitar a liberdade de expressão por ofensas reais ou imaginárias, elementos igualmente no âmbito da opinião, aparece como uma contradição inerente àqueles que exigem espaço para professar sua fé de forma pública. 
A fraqueza do sistema democrático parece residir, de forma contraditória, em sua força: é na multiplicidade de crenças e opiniões, de ideologias e ideias políticas, que se encontra o bacilo que pode enfraquecê-lo. Na tentativa de frear algumas opiniões que parecem se contrapor a um senso comum, decisões retrógradas surgem como uma aparente solução a um conflito exposto. Quando ideias de cunho autoritário passam a ser vistas como possíveis soluções para os desafios democráticos, é quando se principia a queda do próprio Estado de direito.

\section{Referências}

BERGSON, Henri. O Riso. Rio de Janeiro: Jorge Zahar, 2001.

BERLIN, Isaiah. Two concepts of liberty. Oxford: Clarendon, 2004.

BLITT, Barry. The Politics of Fear. In: The New Yorker. 21 Jul. 2008. p. 1.

BRASIL. Decreto-Lei n. 9.504, de 30 de set. 1997. Disponível em < http://www.planalto.gov.br/ccivil_03/leis/L9504.htm>.

BYTWERK, Randall L. Julius Streicher|; Nazi Editor of the notorious anti-semitic newspaper Der Stürmer. New York: Cooper Square, 2001.

COCO et. al. In: Charlie Hebdo. Paris, 19 de setembro de 2012. p. 14.

DAWKINS, Richard. Deus, um delírio. São Paulo: Cia. das Letras, 2007.

DIÈNE, Doudou. Racism, racial discrimination, xenophobia and all forms of discrimination: situation of Muslims and Arab peoples in various parts of the world. Report to the U.N. Commission on Human Rights. 13 Feb. 2006. Disponível em: <http://ap.ohchr.org/documents/dpage_e.aspx?m=92>.

ERHARDT, Elmar. Kunstfreiheit und Strafrecht: Zur Problematik satirischer Ehrverletzungen. Heidelberg: R. v. Decker, 1988.

FREUD, Sigmund. Der witz und seine beziehung zum Unbewussten: der humor. Frankfurt am Main: Fischer, 2006. 
GALLUP Institute. Religious perceptions in America. Washington, 2009. p. 8. Disponível em: <http://www.gallup.com/strategicconsulting/153434/ENGLISH-First-PDF-Test.aspx>. Acessado em: 15 de nov. de $2012 a$.

GALLUP Institute. Islamophobia: understanding anti-muslim sentiment in the west. Washington, 2011. Disponível em <http://www.gallup.com/poll/157082/islamophobiaunderstanding-anti-muslim-sentiment-west.aspx\#1>. Acessado em 17 de nov. de 2012b.

JORNAIS dinamarqueses republicam charge polêmica de Maomé. Estadão, São Paulo, 13 fev. 2008. Disponivel em:: <http://www.estadao.com.br/noticias/geral,jornaisdinamarqueses-republicam-charge-polemica-de-maome,123851>. Acessado em 13 de nov. de 2012.

JUIZ de São Paulo ordena que vídeo anti-Islã seja retirado do ar. Gazeta do Povo, 25 set. 2012. Disponível em:

<http://www.gazetadopovo.com.br/mundo/conteudo.phtml?id=1301123\&tit=Juiz-de-SaoPaulo-ordena-que-video-anti-Isla-seja-retirado-do-ar>. Acessado em 13 de nov. de 2012.

HIMMELFARB, Gertrudes. Os caminhos para a modernidade. São Paulo: É Realizações, 2011.

HUNTINGTON, Samuel. O choque de civilizações. Rio de Janeiro: Objetiva, 1997.

ISRAEL, Jonathan. Iluminismo radical: a filosofia e a construção da modernidade (1651750). São Paulo: Madras, 2009.

JEFFERSON, Thomas. The Virginia Statute for religious freedom. Fredericksburg. 1777. Disponível em: <http://en.wikisource.org/wiki/Virginia_Statute_for_Religious_Freedom>

KABANDA, Marcel. Kangura: the Triumph of Propaganda Refined. In: THOMPSON, Allan. (Org.) The Media and the Rwanda Genocide. London: Pluto, 2007. p. 62-72.

KANT, Immanuel. Crítica da faculdade do juízo. Rio de Janeiro: Forense Universitária, 2010.

KLAUSEN, Jytte. The cartoons that shook the World. New Haven: Yale Univ. Press, 2009.

KORNELIUS, Stefan. Das Bild vom Feind. Süddeutsche Zeitung. n. 30. 6 Fev. 2006.

LIEBEL, Vinícius. Politische Karikaturen und die Grenzen des Humors und der Gewalt eine dokumentarische Analyse der nationalsozialistischen Zeitung ,Der Stürmer‘.

Opladen: Budrich Unipress, 2011a. 
LIEBEL, Vinícius.. Entre sentidos e Interpretações: apontamentos sobre a análise documentária de imagens. Revista ETD, Campinas, v. 12, n. 2. 2011 b.

MILL, John Stuart. Sobre a liberdade. Rio de Janeiro: Nova Fronteira, 2011.

MONTESQUIEU. De l'esprit des lois. Flammarion: Paris, 2008.

PÄGE, Herbert. Karikaturen in der Zeitung: Engagierter Bildjournalismus oder opportunistisches Schmuckelement? Aachen: Shaker Media, 2007.

PROTESTOS contra charges do profeta Maomé deixam 9 mortos. Folha Online, Sâo Paulo, 07 fev. 2006. Disponível em:

<http://www1.folha.uol.com.br/folha/mundo/ult94u92367.shtml>. Acessado em 13 de nov. de 2012.

RAUCH, Jonathan. Kindly inquisitors. Chicago: University of Chicago, 1993.

RAWLS, John. Justiça e democracia. São Paulo: Martins Fontes, 2002.

ROSANVALLON, Pierre. La Contre-démocratie : la politique à l'âge de la défiance. Paris : Seuil, 2006

SHOWALTER, Dennis. Little man, what now? Hamden: Achon Books, 1982.

SUPREMO TRIBUNAL FEDERAL. STF confirma suspensão de dispositivos da Lei Eleitoral sobre o humor. 2010. Disponível em :

<http://www.stf.jus.br/portal/cms/verNoticiaDetalhe.asp?idConteudo=160528 >. Acessado em 13 de nov. de 2012.

TÖPFFER, Rodolphe. Essai de physiognomie. Paris : Editions de l’Eclat, 2003.

WASHINGTON, Jesse. Presidência de Obama faz com que chargistas tenham que aliviar o traço. O Globo. Rio de Janeiro, 24 fev. 2009. Disponível em: < http://g1.globo.com/Noticias/PopArte/o,,MUL1012379-7084,00.html>.

WEBER, Karsten. Freie Meinungsäußerung als Frage und Aufforderung. In: DEBATIN, Bernhardt (Org.). Der Karikaturenstreit und die Pressefreiheit: Wert- und Normenkonflikte in der globalen Medienkultur. Münster: LIT, 2007.

WESTERGAARD, Kurt. Muhammed. In: Jylliands Posten. 30. Sep. 2005. p.3. 
Recebido em 14/07/2016 Aprovado em 22/08/2016

Universidade do Estado de Santa Catarina - UDESC

Programa de Pós-Graduação em História - PPGH

Revista Tempo e Argumento Volume 08 - Número 18 - Ano 2016 tempoeargumento@gmail.com 